\title{
Mitral annuloplasty ring suture forces: Impact of surgeon, ring, and use conditions
}

Eric L. Pierce, BS, ${ }^{a}$ Charles H. Bloodworth IV, BS, ${ }^{a}$ Andrew W. Siefert, PhD, ${ }^{\text {a,b }}$ Thomas F. Easley, MS, ${ }^{a}$ Tetsushi Takayama, MD, ${ }^{c}$ Tomonori Kawamura, MD, ${ }^{c}$ Robert C. Gorman, MD, Joseph H. Gorman III, MD, ${ }^{c}$ and Ajit P. Yoganathan, $\mathrm{PhD}^{\mathrm{a}}$

\section{ABSTRACT}

Objective: The study objective was to quantify the effect of ring type, ring-annulus sizing, suture position, and surgeon on the forces required to tie down and constrain a mitral annuloplasty ring to a beating heart.

Methods: Physio (Edwards Lifesciences, Irvine, Calif) or Profile 3D (Medtronic, Dublin, Ireland) annuloplasty rings were instrumented with suture force transducers and implanted in ovine subjects $(\mathrm{N}=23)$. Tie-down forces and cyclic contractile forces were recorded and analyzed at 10 suture positions and at 3 levels of increasing peak left ventricular pressure.

Results: Across all conditions, tie-down force was $2.7 \pm 1.4 \mathrm{~N}$ and cyclic contractile force was $2.0 \pm 1.2 \mathrm{~N}$. Tie-down force was not meaningfully affected by any factor except surgeon. Significant differences in overall and individual tie-down forces were observed between the 2 primary implanting surgeons. No other factors were observed to significantly affect tie-down force. Contractile suture forces were significantly reduced by ring-annulus true sizing. This was driven almost exclusively by Physio cases and by reduction along the anterior aspect, where dehiscence is less common clinically. Contractile suture forces did not differ significantly between ring types. However, when undersizing, Profile 3D forces were significantly more uniform around the annular circumference. A suture's tie-down force did not correlate to its eventual contractile force.

Conclusions: Mitral annuloplasty suture loading is influenced by ring type, ring-annulus sizing, suture position, and surgeon, suggesting that reports of dehiscence may not be merely a series of isolated errors. When compared with forces known to cause suture dehiscence, these in vivo suture loading data aid in establishing potential targets for reducing the occurrence of ring dehiscence. (J Thorac Cardiovasc Surg 2018;155:131-9)

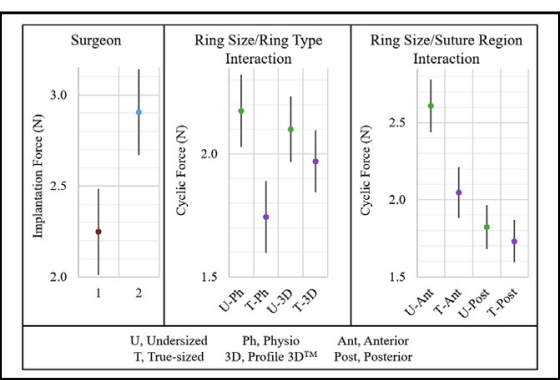

Annuloplasty suture forces are affected by device characteristics, surgeon, and anatomy.

\section{Central Message}

Forces experienced by mitral annuloplasty sutures are modulated by ring type, ring-annulus sizing, suture position, and surgeon, establishing potential targets for reducing the incidence of dehiscence.

\section{Perspective}

Reports of suture dehiscence may not be merely a series of unrelated surgical errors Repeatable differences in suture force according to ring selection, suture position, and surgeon suggest suture retention may be improved by novel ring designs or increased attention to knot-tying technique. Further, regulation of valvular implants may benefit from verification of tolerable in vivo anchor loads.

See Editorial Commentaries pages 140 and 142.

\footnotetext{
From ${ }^{\text {a }}$ The Wallace H. Coulter Department of Biomedical Engineering, Georgia Institute of Technology and Emory University, Atlanta, Ga; ' Inc, Alpharetta, Ga; and ${ }^{\mathrm{c}}$ Gorman Cardiovascular Research Group, Perelman School of Medicine, University of Pennsylvania, Philadelphia, Pa.

This study was partially supported by grants from the National Science Foundation (DGE-1148903; to E.L.P.), the National Heart, Lung, and Blood Institute (R01HL113216), and the National Center for Advancing Translational Sciences (UL1TR000454).

Received for publication Jan 27, 2017; revisions received May 30, 2017; accepted for publication June 15, 2017; available ahead of print July 18, 2017.

Address for reprints: Ajit P. Yoganathan, PhD, 387 Technology Circle NW, Suite 200, Atlanta, GA 30313 (E-mail: ajit.yoganathan@bme.gatech.edu).

$0022-5223 / \$ 36.00$

Copyright (c) 2017 by The American Association for Thoracic Surgery

http://dx.doi.org/10.1016/j.jtcvs.2017.06.036
}

Surgical repair is a common approach to correct ischemic mitral regurgitation (IMR), and its optimal use is the subject of active investigation. ${ }^{1-3}$ Ring or band annuloplasty is central to mitral valve repair. ${ }^{4,5}$ With more than 20

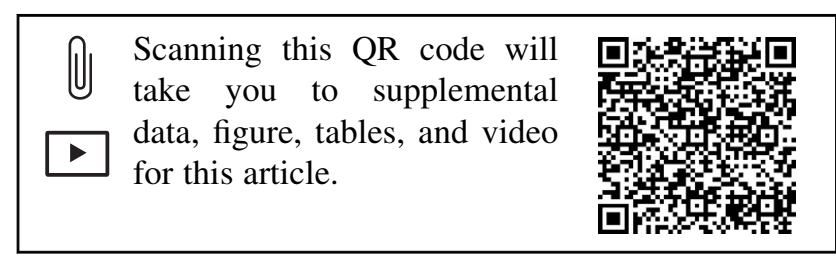




\section{Abbreviations and Acronyms}

ANOVA $=$ analysis of variance

$\mathrm{F}_{\mathrm{C}} \quad=$ cyclic contractile force

$\mathrm{F}_{\mathrm{TD}} \quad=$ tie-down force

IMR = ischemic mitral regurgitation

$\mathrm{LVP}_{\max }=$ maximum left ventricular pressure

commercially available devices in the United States, surgeons performing annuloplasty must select from among a range of shapes, stiffnesses, and sizes. Undersized rigid or semi-rigid ring annuloplasty has been the favored approach for IMR repair. ${ }^{4}$

Although favored, IMR repair durability is generally poor. ${ }^{6,7}$ One increasingly recognized adverse event after IMR repair is annuloplasty suture dehiscence. Among studies of reoperation after failed annuloplasty-based mitral repair, the proportion of failures attributed to annular suture dehiscence is $13 \%$ to $42 \%{ }^{8-10} \mathrm{~A}$ range of reports ${ }^{11-15}$ reveal that suture dehiscence is a pressing challenge across device types. Its consequences may be severe, including device migration, embolization, endocarditis, recurrent regurgitation, and increased patient mortality. ${ }^{14-16}$

The factors contributing to annuloplasty suture dehiscence remain largely unclear. Although clinical reports may be naturally attributed to surgical error, multiple groups have questioned the extent to which dehiscence likelihood is determined systematically. ${ }^{17-20}$ Quantification of such systematic factors would offer 2 principal benefits. First, in a review of recent literature (with mean patient follow-up $>1$ year), Khamooshian and colleagues $^{21}$ found insufficient evidence to establish any superior ring type, in terms of New York Heart Association class and ventricular function. Amidst such uncertainty, differences in anchoring performance would constitute a basis to discriminate among existing rings. Second, data describing the factors contributing to suture dehiscence would be instrumental in the development of controls to prohibit its occurrence.

Evidence is mounting that suture dehiscence likelihood can be targeted in this way. For example, using a deterministic simulation, Wong and colleagues ${ }^{20}$ noted differences between 2 commercial rings in terms of virtual suture force in each posterior annulus segment (with peak difference $>0.5 \mathrm{~N}$ at end diastole). By using a live ovine model coupled to in vitro imaging, we recently found that the clinical tendency for dehiscence from the posterior annulus $^{12-14,22}$ likely derives from this region's reduced collagen density. ${ }^{18}$ We further observed a stark redistribution of force after a single suture's tear-out to its 2 adjacent sutures, highlighting a potential dehiscence cascade mechanism. ${ }^{17}$ These initial findings now motivate our pursuit to understand the impact of ring type, ring-annulus sizing, suture position, surgeon, and left heart hemodynamic conditions on suture loading. To this end, the present study sought to quantify suture forces required to tie-down and constrain true-sized and undersized Physio (Edwards Lifesciences, Irvine, Calif) and Profile 3D (Medtronic, Dublin, Ireland) rings within the ovine heart.

\section{MATERIALS AND METHODS}

A video description of the methodology used herein is provided in Video 1.

\section{Suture Force Measurement}

To measure tension in individual annuloplasty sutures, novel transducers were previously developed and demonstrated (Figure 1, A). ${ }^{19}$ Transducers were designed to report suture tension as a positive force. As previously described, transducers were calibrated with known forces exceeding those anticipated in vivo. Sets of transducers $(\mathrm{N}=10)$ were affixed to Physio or Profile 3D annuloplasty rings. Transducers were positioned at the left trigone, right trigone, and at evenly spaced locations around the remaining circumference (Figure 1, $B-D$ ). The flaccid annulus was sized using the sizer set corresponding to either ring type; either an undersized ( 2 sizes down) or true-sized ring of that type was selected. Transducer signals were zeroed before implantation in the cardioplegic heart. To implant the instrumented ring, one $2-0 \mathrm{Ti} \cdot$ Cron mattress suture (Medtronic) was passed through and tied to each transducer (ie, 10 total sutures) via a method analogous to normal attachment to a ring's suture cuff (Figure 1,E).

Data were collected from 23 healthy Dorsett hybrid sheep. All animals received care in compliance with protocols approved by the Institutional Animal Care and Use Committee at the University of Pennsylvania, in accordance with the guidelines for humane care. ${ }^{23}$ Surgical protocols were performed by experienced mitral surgeons. For additional details on force transducer technology and experimental procedures, see Supplemental Materials and Methods or our previous publications. ${ }^{18,19}$

\section{Tie-Down and Cyclic Contractile Force Analyses}

For each suture, tie-down force $\left(\mathrm{F}_{\mathrm{TD}}\right)$ was computed as the difference in force immediately before and after its tie-down (Figure 2, A). Cyclic contractile force $\left(\mathrm{F}_{\mathrm{C}}\right)$ was computed as the difference between the minimum and the maximum force recorded within a cardiac cycle (Figure 2,B), averaged across 10 consecutive cardiac cycles. These forces were computed for 3 levels of maximum left ventricular pressure $\left(\mathrm{LVP}_{\max }\right)$, namely, 100,125 , or $150 \mathrm{~mm} \mathrm{Hg}$. $\mathrm{F}_{\mathrm{C}}$ represents the tensile force to which a suture is subjected in the beating heart. It may be attributable to a range of factors, including annular bending out-of-plane or contraction in-plane, myocardial fiber dimension change, and aortic root expansion.

Averages are reported as mean \pm standard deviation. Statistical analyses included Levene's test for differences in variance between ring types (SPSS, IBM Corporation, Armonk, NY), correlation analyses on

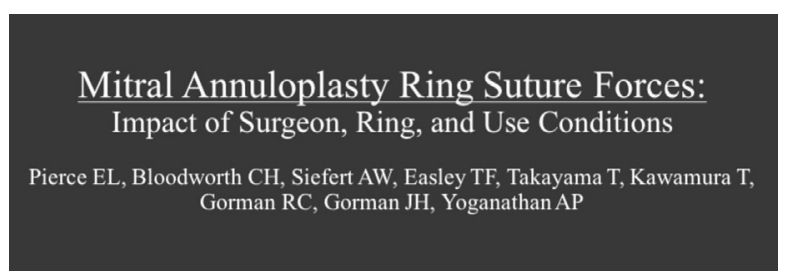

VIDEO 1. A summary of the study's overall goal and approach, highlighting key tools, experimental procedures, and data types. Video available at: http://www.jtcvsonline.org/article/S0022-5223(17)31355-7/addons. 


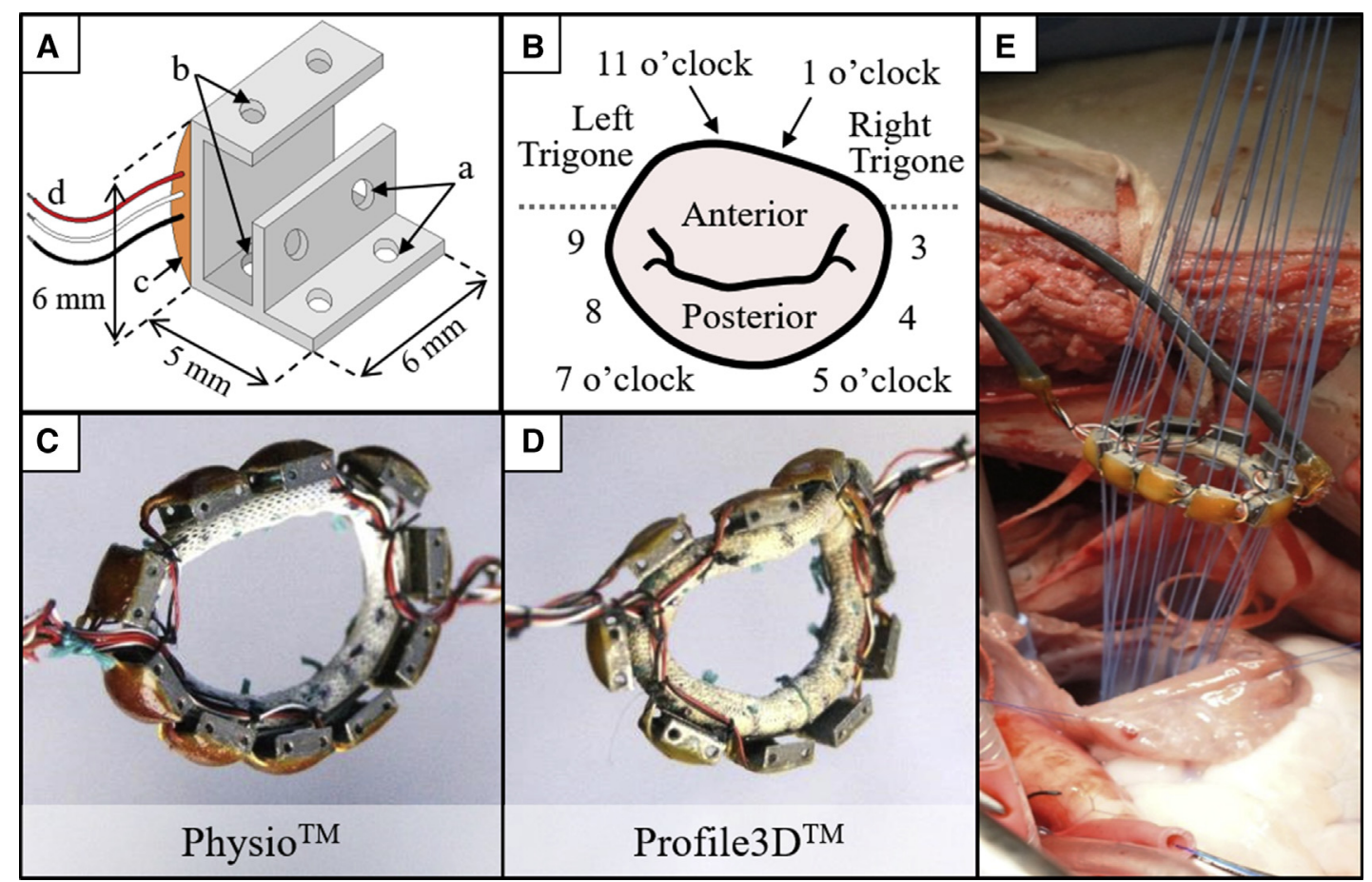

FIGURE 1. Design and application of suture force transducers, first reported by Siefert and colleagues. ${ }^{19}$ A, Transducer design schematic, illustrating suture holes for ring fixturing $(a)$, passages for annuloplasty sutures $(b)$, force-sensing strain gage $(c)$, and wiring $(d)$. B, Locations of transducers around ring/annulus. One suture was placed through each of 10 transducers for a given ring. Dotted line: boundary between anterior and posterior sutures for regional analysis. C and D, Instrumented rings. E, Device implantation.

$\mathrm{F}_{\mathrm{TD}}$ versus $\mathrm{F}_{\mathrm{C}}$ (MATLAB, MathWorks, Natick, Mass), and 4 multiway analysis of variance (ANOVA) models, with Tukey's honestly significant difference tests, applied to $\mathrm{F}_{\mathrm{TD}}$ or $\mathrm{F}_{\mathrm{C}}$ (MATLAB). When Levene's test identified heteroscedasticity, its impact on ANOVA accuracy was confirmed to be negligible, according to published references. ${ }^{24-27}$ ANOVA models are described in Table 1.

\section{RESULTS}

A summary of key animal and procedural characteristics and hemodynamic conditions during beating heart measurements is presented in Table 2. Across all truesized or undersized annuloplasty cases, the postprocedural increase in transmitral gradient was $0.9 \pm 0.4 \mathrm{~mm} \mathrm{Hg}$ or $1.9 \pm 1.6 \mathrm{~mm} \mathrm{Hg}$, respectively (measured at $100 \mathrm{~mm} \mathrm{Hg}$ $\mathrm{LVP}_{\max }$ ). The $\mathrm{F}$ and $P$ values obtained for all ANOVA models are shown in Table E1.

\section{Tie-Down Force}

In early cases using the Physio ring, forces were not recorded during suture tie-down. $\mathrm{F}_{\mathrm{TD}}$ was measured in 4 of 10 Physio and 13 of 13 Profile 3D cases. Among these 17 cases, $\mathrm{F}_{\mathrm{TD}}$ was $2.7 \pm 1.4 \mathrm{~N}$ (range, 0.0-8.0 N). On the basis of the ANOVA model 1, it was found that ring type, ring-annulus sizing, and suture position did not significantly affect $F_{T D}$. Furthermore, no significant pairwise interactions among these factors were found.
Next, noting that no significant differences due to ring type or ring-annulus sizing were found, and desiring to examine the impact of surgeon on $\mathrm{F}_{\mathrm{TD}}$, ANOVA model 2 was applied to a subset of 11 Profile 3D cases. These were performed by either of 2 surgeons ( $\mathrm{N}=5$ or 6 each), whereas no other surgeon performed more than 2 cases for which $\mathrm{F}_{\mathrm{TD}}$ was collected. As shown in Figure 3, across all positions, surgeon 2 applied $29 \%$ more $\mathrm{F}_{\mathrm{TD}}$ than surgeon $1(2.9 \pm 1.2 \mathrm{~N}$ vs $2.2 \pm 1.4 \mathrm{~N} ; P=.006)$. Across surgeons, only 1 pairwise significant difference was found among positions: The 1 o'clock sutures endured greater $\mathrm{F}_{\mathrm{TD}}$ than 5 o'clock sutures $(3.6 \pm 0.8 \mathrm{~N}$ vs $1.9 \pm 0.9 \mathrm{~N}, P=.048)$. In addition, 1 o'clock sutures nearly achieved significance versus multiple other positions. Interaction between surgeon and position was observed; notably, placement of the final 9 o'clock suture contributed greater $\mathrm{F}_{\mathrm{TD}}$ when performed by surgeon 2 $(3.9 \pm 1.2 \mathrm{~N}$ vs $1.3 \pm 0.6 \mathrm{~N}, P=.035)$.

\section{Cyclic Contractile Force}

Averaged across all conditions, $\mathrm{F}_{\mathrm{C}}$ was $2.0 \pm 1.2 \mathrm{~N}$ (range, 0.2-7.3 N). $\mathrm{F}_{\mathrm{C}}$ from each ring type, ring-annulus sizing, and suture position at $\mathrm{LVP}_{\max }=125 \mathrm{~mm} \mathrm{Hg}$ are presented in Figure 4, $A$ and $B$. These values are provided for each $\mathrm{LVP}_{\max }$ in Table E2.

Results from ANOVA model 3 are given in Figure 4, $C$ to $H$. Consistent with prior findings, ${ }^{18,19}$ significant increases in 


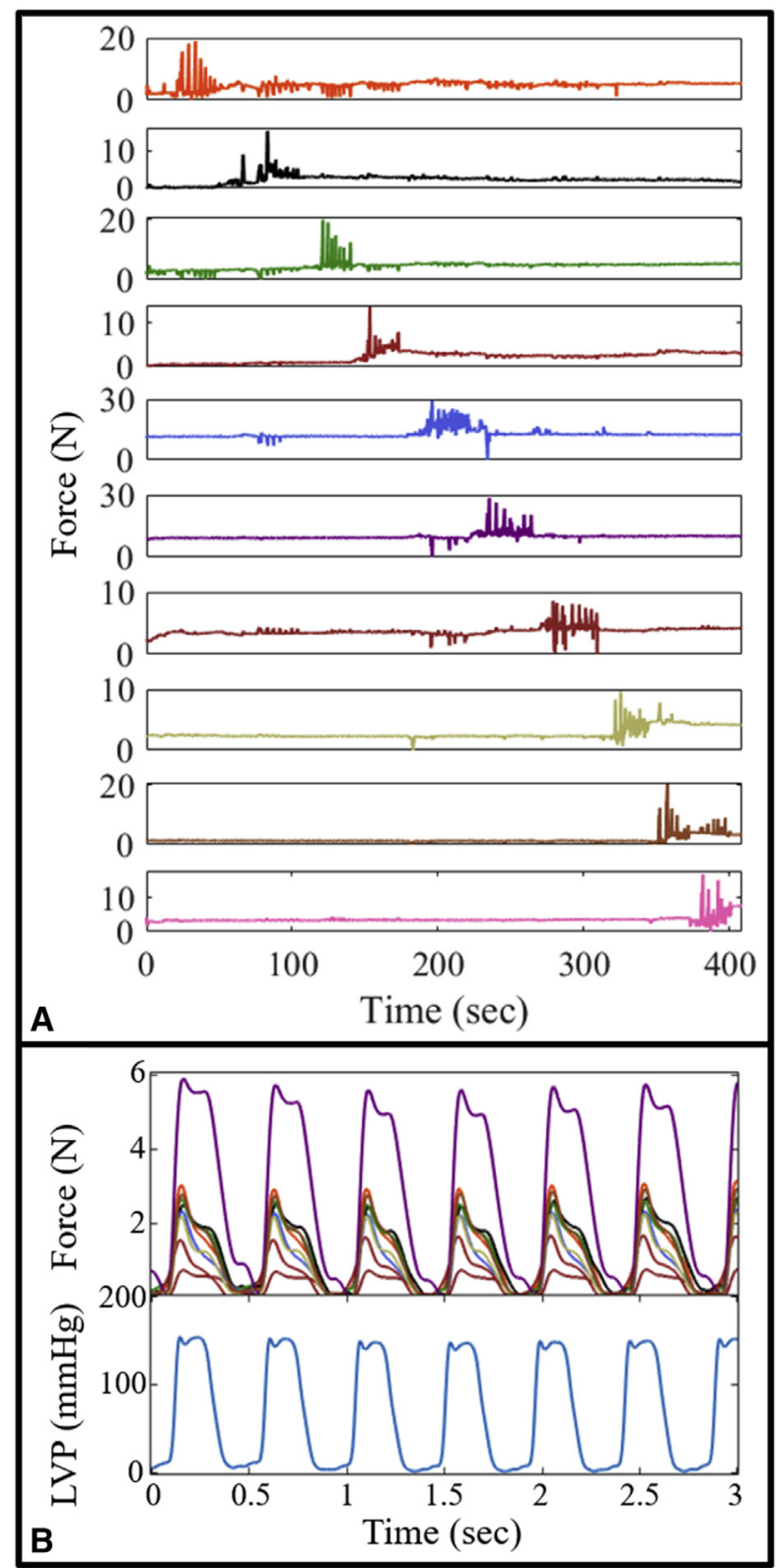

FIGURE 2. A, Representative data used for $\mathrm{F}_{\mathrm{TD}}$ measurement. Sutures were tied first to left trigone, then right trigone, then clockwise from 11 o'clock. $\mathrm{F}_{\mathrm{TD}}$ was computed as the force differential immediately before/after tie-down (tie-down visible here as a series of quick spikes). $\mathrm{B}$, Representative data used for $\mathrm{F}_{\mathrm{C}}$ measurement, revealing strong coupling between LVP and suture force. $\mathrm{F}_{\mathrm{C}}$ computed as the maximum force range within a cardiac cycle, averaged across 10 consecutive cycles. LVP, Left ventricular pressure.

$\mathrm{F}_{\mathrm{C}}$ were observed with each level of $\mathrm{LVP}_{\max }$. In order of increasing $\mathrm{LVP}_{\max }, \mathrm{F}_{\mathrm{C}}$ was $1.7 \pm 1.0 \mathrm{~N}, 2.0 \pm 1.1 \mathrm{~N}$, and $2.3 \pm 1.2 \mathrm{~N}(P=.003$ and $P=.029$ for 100 vs $125 \mathrm{~mm} \mathrm{Hg}$ and 125 vs $150 \mathrm{~mm} \mathrm{Hg}$, respectively). True sizing reduced $\mathrm{F}_{\mathrm{C}}$ by a relatively small yet significant margin (undersized vs true sized: $2.1 \pm 1.2 \mathrm{~N}$ vs $1.9 \pm 1.0 \mathrm{~N}, P<.001$ ). In contrast, ring type did not significantly affect mean
TABLE 1. Description of analysis of variance models

\begin{tabular}{|c|c|c|}
\hline Model & $\begin{array}{c}\text { Dependent } \\
\text { variable }\end{array}$ & Independent variables \\
\hline 1 & $\mathrm{~F}_{\mathrm{TD}}$ & $\begin{array}{l}\text { Ring type, ring-annulus sizing, } \\
\text { suture position }\end{array}$ \\
\hline 2 & $\mathrm{~F}_{\mathrm{TD}} *$ & Surgeon, suture position \\
\hline 3 & $\mathrm{~F}_{\mathrm{C}}$ & $\begin{array}{l}\mathrm{LVP}_{\text {max }} \text {, ring type, ring-annulus } \\
\text { size, suture position }\end{array}$ \\
\hline 4 & $\mathrm{~F}_{\mathrm{C}}$ & $\begin{array}{l}\mathrm{LVP}_{\text {max }} \text {, ring type, ring-annulus } \\
\text { size, suture region } \dagger\end{array}$ \\
\hline
\end{tabular}

Note, each model was tested first without interaction terms to assess main effects, then with all possible pairwise interactions. $F_{T D}$, Tie-down force; $F_{C}$, cyclic contractile force; $L V P_{\max }$, maximum left ventricular pressure. *This model examined a subset of 11 Profile 3D (Medtronic, Dublin, Ireland) cases, performed by either of 2 surgeons (no other surgeon performed $>2$ cases for which $\mathrm{F}_{\mathrm{TD}}$ was collected). $\dagger$ Sutures grouped as anterior (including left trigone, 11 o'clock, 1 o'clock, and right trigone) or (posterior, including 3-9 o'clock).

$\mathrm{F}_{\mathrm{C}}$ (Physio $2.0 \pm 1.2$ vs Profile 3D $2.0 \pm 1.1 \mathrm{~N}, P=.290$ ). With respect to suture position, placement at either trigone significantly increased $\mathrm{F}_{\mathrm{C}}$ versus numerous other positions. After accounting for 2-factor interactions, it was noted that $\mathrm{LVP}_{\max }$ did not significantly interact with any other factor, revealing that elevated $\mathrm{LVP}_{\max }$ affected $\mathrm{F}_{\mathrm{C}}$ uniformly. Ring type and ring-annulus sizing interacted. With Physio rings, true sizing conferred significant $\mathrm{F}_{\mathrm{C}}$ reduction (undersized Physio $2.2 \pm 1.4 \mathrm{~N}$ vs true-sized Physio $1.7 \pm 0.9 \mathrm{~N}$, $P<.001$ ); undersized Profile 3D and true-sized Profile 3D did not differ significantly $(2.1 \pm 1.1 \mathrm{~N}$ vs $2.0 \pm 1.1 \mathrm{~N}$, $P=.545)$. Significant interactions also existed between suture position and either ring type or ring-annulus sizing. These data are provided in Figure E1, but are more clearly understood after grouping sutures by region.

Thus, ANOVA model 4 replicated model 3, but grouped sutures as anterior or posterior. Anterior sutures endured greater $\mathrm{F}_{\mathrm{C}}$ than posterior $(2.3 \pm 1.3 \mathrm{~N}$ vs $1.8 \pm 1.0 \mathrm{~N}$, $P<.001)$. No significant interaction was observed between suture region and ring type $(P=.731)$. Interaction between suture region and ring-annulus sizing was more complex (Figure $4, H$ ). Anterior $\mathrm{F}_{\mathrm{C}}$ again exceeded posterior, across conditions (undersized-anterior $2.6 \pm 1.3$ vs undersized-posterior $1.8 \pm 1.1 \mathrm{~N}, P<.001$; true sized-anterior $2.1 \pm 1.2$ vs true sized-posterior $1.7 \pm 0.9 \mathrm{~N}, P=.031)$. However, the aforementioned capacity for true sizing to relieve $F_{C}$ was driven exclusively by differences along the anterior annulus (undersized-anterior vs true sized-anterior, $P<.001$; undersized-posterior vs true sized-posterior, $P=.812$ ).

Last, it was noted that when undersizing, use of the Profile 3D led to more uniform $F_{C}$ across positions. Pooled standard deviation was significantly higher for the undersized Physio ring than the undersized Profile 3D (0.9 vs $0.5 \mathrm{~N}, P=.036$, Levene's test). No such differences were observed when true sizing. 
TABLE 2. Dataset summary

\begin{tabular}{|c|c|c|c|c|}
\hline & Undersized Physio ring* & True-sized Physio ring & $\begin{array}{c}\text { Undersized } \\
\text { Profile 3D ring } \\
\end{array}$ & True-sized Profile 3D ring \\
\hline Sample size & 5 & 5 & 6 & 7 \\
\hline Surgeon 1 frequency & 0 & 0 & 1 & 5 \\
\hline Surgeon 2 frequency & 0 & 0 & 3 & 2 \\
\hline $\begin{array}{l}\text { All other surgeons' combined } \\
\text { frequency }\end{array}$ & 5 & 5 & 2 & 0 \\
\hline Animal weight (kg) & $58.2 \pm 12.4$ & $58.2 \pm 10.6$ & $57.0 \pm 5.8$ & $57.4 \pm 6.8$ \\
\hline Annulus size & $30.0 \pm 0.0$ & $28.8 \pm 2.3$ & $30.0 \pm 0.0$ & $27.7 \pm 1.8$ \\
\hline Ring size & $26.0 \pm 0.0$ & $28.8 \pm 2.3$ & $26.0 \pm 0.0$ & $27.7 \pm 1.8$ \\
\hline $\begin{array}{l}\mathrm{HR} \text { at } \mathrm{LVP}_{\max }=100 \mathrm{~mm} \mathrm{Hg} \\
\text { (beats/min) }\end{array}$ & $110.8 \pm 14.1$ & $106.0 \pm 25.1$ & $126.5 \pm 24.6$ & $136.0 \pm 26.8$ \\
\hline $\begin{array}{l}\mathrm{HR} \text { at } \mathrm{LVP}_{\max }=125 \mathrm{~mm} \mathrm{Hg} \\
\quad \text { (beats/min) }\end{array}$ & $122.2 \pm 12.9$ & $117.0 \pm 25.0$ & $130.2 \pm 25.8$ & $148.1 \pm 23.4$ \\
\hline $\begin{array}{l}\mathrm{HR} \text { at } \mathrm{LVP}_{\max }=150 \mathrm{~mm} \mathrm{Hg} \\
\text { (beats/min) }\end{array}$ & $133.6 \pm 15.4$ & $126.2 \pm 25.5$ & $137.8 \pm 33.2$ & $159.3 \pm 22.3$ \\
\hline
\end{tabular}

$H R$, Heart rate; $L V P_{\max }$, maximum left ventricular pressure. *Edwards Lifesciences, Irvine, Calif. †Medtronic, Dublin, Ireland.

\section{Tie-Down and Contractile Force Correlation}

To understand the extent to which force used to tie-down a suture dictates the eventual cyclic contractile force $\left(\mathrm{F}_{\mathrm{C}}\right)$ on that suture, correlation between $\mathrm{F}_{\mathrm{TD}}$ and $\mathrm{F}_{\mathrm{C}}$ was investigated. Among all 170 sutures for which $\mathrm{F}_{\mathrm{TD}}$ was recorded, linear regression was conducted between $\mathrm{F}_{\mathrm{TD}}$ and the corresponding $\mathrm{F}_{\mathrm{C}}$ at $\mathrm{LVP}_{\max }=125 \mathrm{~mm} \mathrm{Hg}$ (Figure 5), revealing $\mathrm{R}^{2}=0.003$.

\section{DISCUSSION}

Although clinical reports of suture dehiscence after mitral annuloplasty may be easy to dismiss as a result of mere surgical error, the present study demonstrated that the total force acting on annuloplasty sutures varies significantly with fundamental surgical choices (ie, ring type, ring-annulus sizing, and knot-tying technique) and use conditions (ie, circumferential suture position and

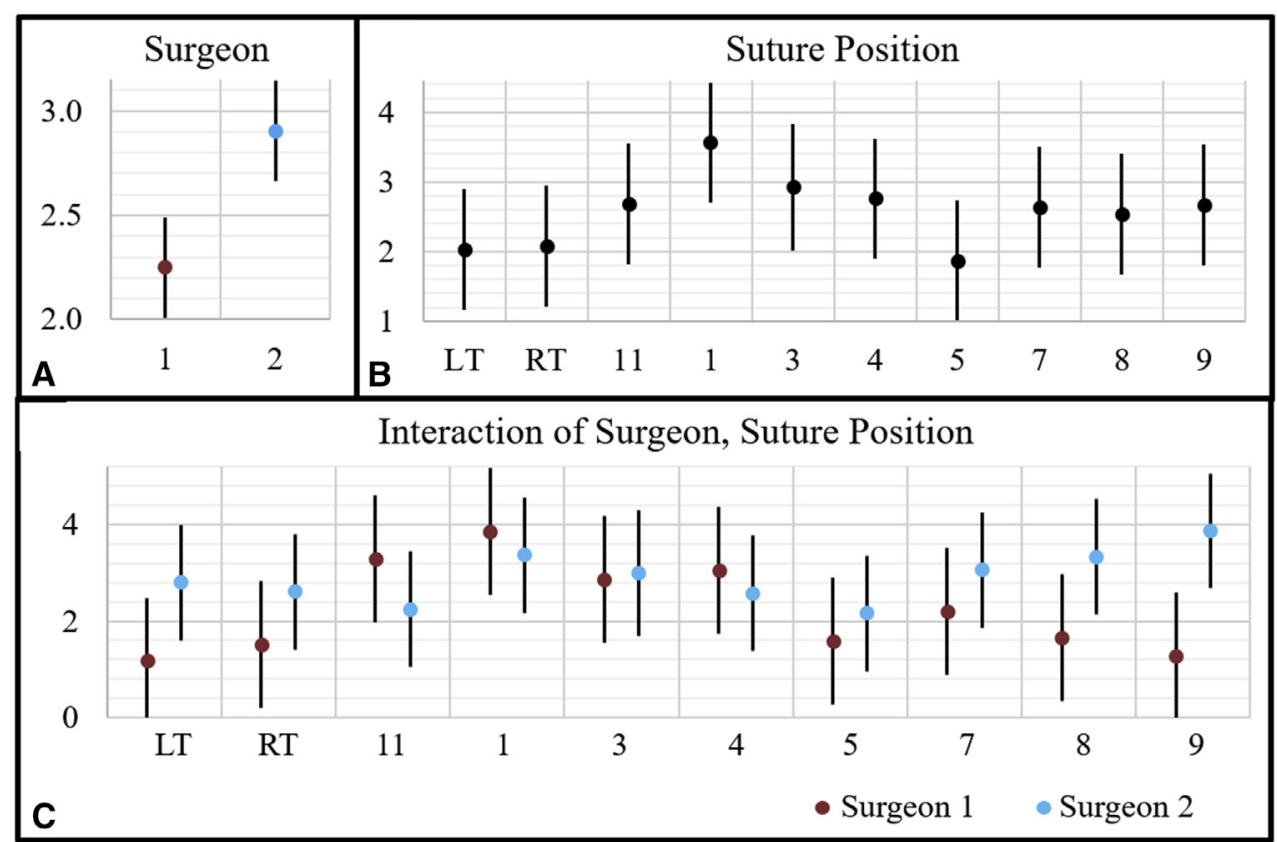

FIGURE 3. $\mathrm{F}_{\mathrm{TD}}$ ANOVA results, from a cohort of 11 Profile 3D (Medtronic, Dublin, Ireland) cases split 5:6 among 2 surgeons (A). All plots reveal means and $95 \%$ confidence intervals of force $[\mathrm{N}]$; pairs whose $95 \%$ confidence intervals do not overlap differ significantly $(P<.05)$. B and $\mathrm{C}$, Shown in order of suture implantation. $L T$, Left trigone; $R T$, right trigone. 


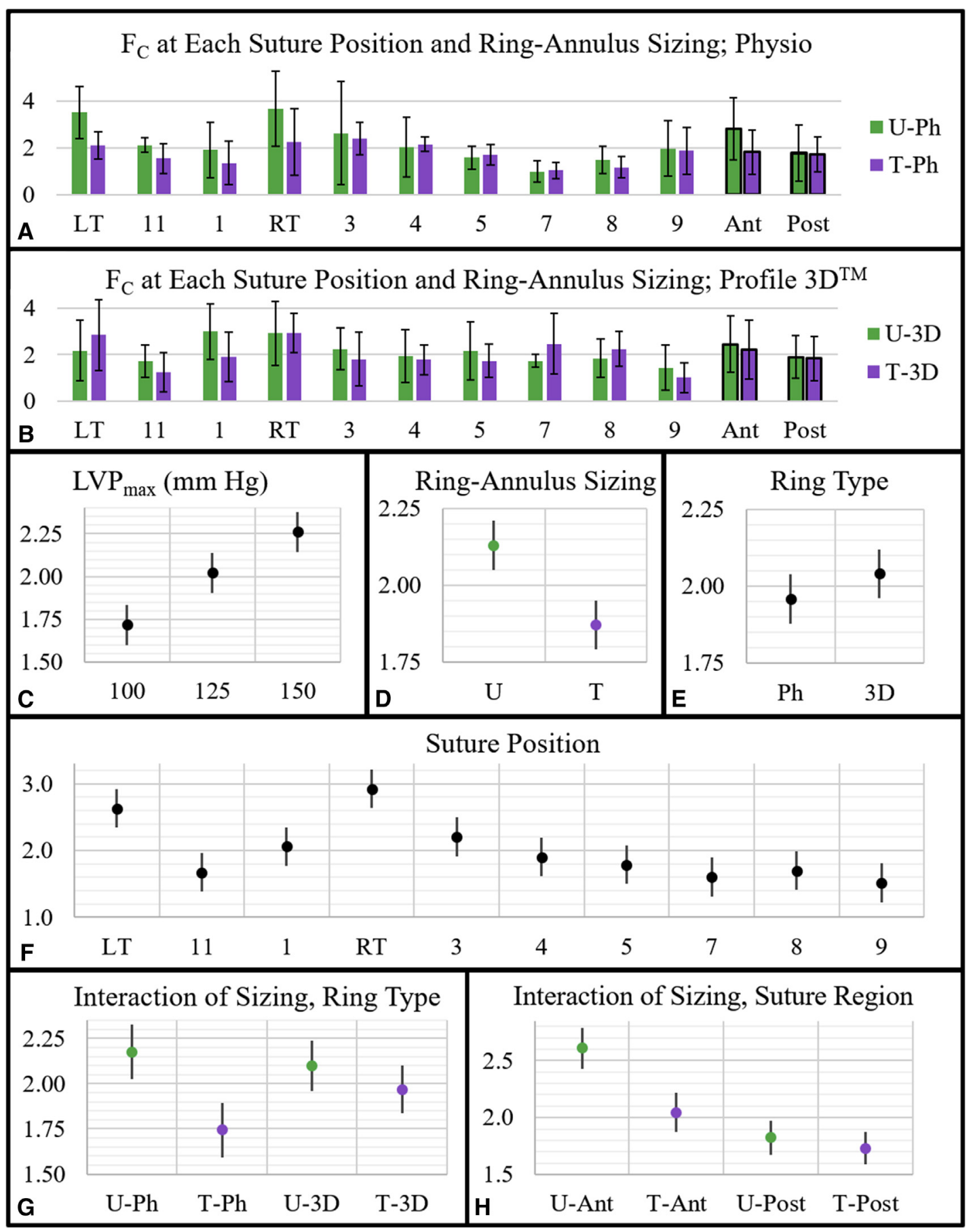

FIGURE 4. $\mathrm{A}$ and $\mathrm{B}, \mathrm{F}_{\mathrm{C}}$ data from each ring type/ring-annulus sizing combination. Shown: force mean \pm standard deviation [N]. Data are shown in circumferential order. Grouped $\mathrm{F}_{\mathrm{C}}$ are presented at right. Left trigone-right trigone, anterior; 3-9 o'clock, posterior. C-H, $\mathrm{F}_{\mathrm{C}}$ ANOVA results. All plots reveal force means and $95 \%$ confidence intervals $[\mathrm{N}]$; pairs whose $95 \%$ confidence intervals do not overlap differ significantly $(P<.05)$. $F_{C}$, Cyclic contractile force; $U$ - $P h$, undersized Physio; $T$ - $P h$, true-sized Physio; $L T$, left trigone; $R T$, right trigone; $L V P_{\max }$, maximum left ventricular pressure; $U$-3D, undersized Profile $3 \mathrm{D}$; $T$-3D, true-sized Profile 3D; U-Ant, undersized-anterior; T-Ant, true sized-anterior; U-Post, undersized-posterior; T-Post, true sized-posterior.

$\left.\mathrm{LVP}_{\max }\right)$. Within their limitations, these data suggest a number of key answers about factors that may contribute to dehiscence, while also raising equally important new questions. Nonsignificance of the correlation between $\mathrm{F}_{\mathrm{TD}}$ and $\mathrm{F}_{\mathrm{C}}$ (Figure 5) suggests that a more loosely tied knot is unlikely to relieve eventual $\mathrm{F}_{\mathrm{C}}$. The relatively high $\mathrm{F}_{\mathrm{TD}}$ magnitudes, compared with $\mathrm{F}_{\mathrm{C}}$, were not anticipated. Mean $\mathrm{F}_{\mathrm{TD}}$ was $2.7 \mathrm{~N}$, versus $2.0 \quad \mathrm{~N}_{\mathrm{C}}$ (averaged 


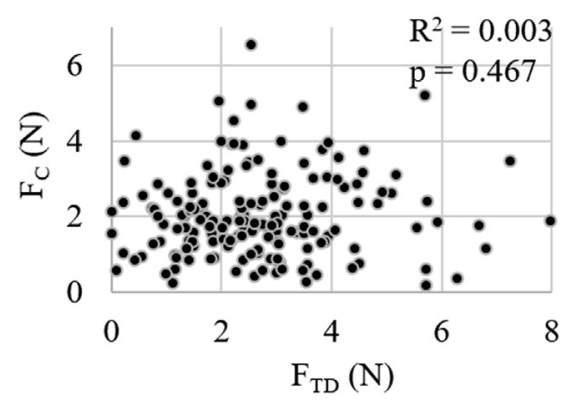

FIGURE 5. Correlation between $\mathrm{F}_{\mathrm{TD}}$ and $\mathrm{F}_{\mathrm{C}} \cdot F_{T D}$, Tie-down force; $F_{C}$, cyclic contractile force.

across all $3 \mathrm{LVP}_{\max }$ levels). This suggests implantation (knot-tying) force may meaningfully affect dehiscence likelihood. Still, the summed quantity, $\mathrm{F}_{\mathrm{C}}+\mathrm{F}_{\mathrm{TD}}$, cannot be assumed to represent the total suture force in the beating heart. It is plausible that $\mathrm{F}_{\mathrm{TD}}$, measured immediately after suture tie-down, evolves postoperatively. Soft tissue viscoelasticity $^{28}$ is known to facilitate stress relaxation and creep; its impact in this context remains unknown. Baseline myocardial tone also may change after weaning from cardiopulmonary bypass and recovery from anesthesia. $^{29}$ Longer term, soft tissue also is capable of active remodeling in response to changes in homeostatic stresses. Such phenomena warrant further investigation.

With respect to suture anchoring, 3 main variables can be influenced by the surgeon. Among these, neither suture selection nor suture placement (bite width, bite depth, or height above leaflet hinge line) was explored in the present study, although we have previously observed dehiscence to occur after likely suture misplacement. ${ }^{17}$ The third variable, knot tying force $\left(\mathrm{F}_{\mathrm{TD}}\right)$, notably did not vary according to ring selection. However, $\mathrm{F}_{\mathrm{TD}}$ was shown to vary both according to circumferential suture position. When exploring Profile 3D rings only, $\mathrm{F}_{\mathrm{TD}}$ at 1 o'clock was highest $\left(36 \%\right.$ above mean $\mathrm{F}_{\mathrm{TD}}$ ), where it significantly exceeded that of 5 o'clock and nearly achieved significance versus multiple other positions. This may be explained by a combination of suture tie-down order (left trigone, then right trigone, then clockwise from 11 o'clock) and ring shape. The 1 o'clock and 9 o'clock sutures were unique in that they were each implanted after both of their respective adjacent sutures. At 1 o'clock, the higher annular collagen content $^{18}$ also might pose more resistance to suture knotting.

Further, significant discrepancies in $\mathrm{F}_{\mathrm{TD}}$ were observed between the 2 primary implanting surgeons in these studies (Figure $3, A$ and $C$ ). Averaged across 6 or 5 procedures, respectively, surgeon 2 applied $29 \%$ more $\mathrm{F}_{\mathrm{TD}}$ overall and $201 \%$ more $\mathrm{F}_{\mathrm{TD}}$ at 9 o'clock compared with surgeon 1. Additional data with more surgeons are warranted. Currently, it remains unclear what suture tie-down strategy, if any, is optimal for anchoring durability. If subsequent investigations are able to identify such an optimum, standardizing to that strategy across surgeons could create substantial value within the scope of the applicable procedures. Recent commentary has highlighted the vital role of surgical training for accurate and precise suture placement as a means to minimize likelihood of dehiscence. $^{30}$ Surgical training may ultimately play a similar role in the context of knot-tying.

$\mathrm{F}_{\mathrm{TD}}$ had no correlation to $\mathrm{F}_{\mathrm{C}}\left(\mathrm{R}^{2}=0.003\right)$. On the basis of these data, a knot tied with less tension would do little to alleviate that suture's additional load during cyclic cardiac contraction. Of note, this finding indicates that although total suture force may be composed of both $\mathrm{F}_{\mathrm{TD}}$ and $\mathrm{F}_{\mathrm{C}}$; the former does not dictate the latter. This may be explained by other as yet unmeasured factors, such as tissue stress relaxation or postoperative myocardial changes, as noted earlier. This advances the notion that suture dehiscence may be driven by more than pure operator error and must be addressed at least in part at the level of device design or selection.

Unlike $\mathrm{F}_{\mathrm{TD}}$, which was unaffected by ring-annulus sizing and type, $F_{C}$ showed significant dependence on ring selection. Use of a true-sized ring reduced $\mathrm{F}_{\mathrm{C}}$. This was expected, because true sizing does less to reshape the annulus. However, it was effective only by way of reducing anterior forces. Of note, mitral annular suture holding strength is greater on the anterior aspect, creating a higher likelihood of dehiscence from the posterior. ${ }^{18}$ Thus, although true sizing certainly appears beneficial for anchoring stability as a whole, it does not directly affect the most pertinent anchoring region. A ring design or approach that preferentially relieves posterior suture forces might achieve superior outcomes with respect to dehiscence.

Contrary to our expectations, use of the saddle-shaped Profile 3D did not significantly relieve $\mathrm{F}_{\mathrm{C}}$ compared with the flatter Physio. Although the exact mechanism for this observation cannot yet be confirmed, we hypothesize that the Profile 3D's increased rigidity compared with the "semi-rigid" Physio plays an important role. A stiffer ring could increase $\mathrm{F}_{\mathrm{C}}$ overall by complying less with cyclic annular motion. Yet, it might also reduce variability between positions by more thoroughly transmitting force around its circumference. We speculate that when undersizing, the impact of the Profile 3D's rigid, saddle-shaped design manifested as forces that are overall slightly reduced but significantly more balanced. However, the benefits of true sizing were meaningfully diminished when using Profile 3D, as the effects of its rigidity dominated. Although the present study provides a direct comparison between 2 prominent commercially available rings, it does not decouple the distinct influences of ring 
shape and stiffness on suture force. Subsequent studies investigating these parameters are now under way.

Greater understanding of the factors affecting mitral ring suture forces will likely support development of improved annuloplasty ring devices. These data may be used to inform device design and testing while providing data for comparison. Currently, annuloplasty rings may cleared for use in the US market via the Food and Drug Administration's $510[\mathrm{k}]$ pathway. Among annuloplasty ring $510[\mathrm{k}]$ submissions to date, suture pullout testing has been nearly ubiquitous. In effect, these comparisons aim to establish that the likelihood of dehiscence is substantially equivalent to existing devices. However, the present study suggests that dehiscence likelihood for a given device may not be solely determined by anchor pullout performance. The spatial distribution of suture forces generated during cardiac contraction varied significantly between the Physio and the Profile 3D. Quantification of in vivo loading may prove an important criterion for device performance assessment; to that end, the present data may function as critical references for devices implanted using annular sutures. In vivo loading may be important to assess in next-generation percutaneous devices, many of which use novel anchor types and placement patterns.

An additional, direct application of the present data may be an input to computational modeling for device design. Computational research is increasingly used in the medical device industry; recent reports by the FDA have embraced its importance in the design process. ${ }^{31,32}$ Modeling of "virtual patients" serves to enable simulation of complex in vivo dynamics, at times offering value to preclinical testing unmatched by in vitro, cadaver, or animal studies. Ground-truth data describing loading of annular sutures (during tie-down of cardiac contraction) may constitute critical boundary conditions or reference points to validate model performance. The present $\mathrm{F}_{\mathrm{TD}}$ data, which did not vary with ring type, is likely applicable to a range of mitral implants. $F_{C}$ data should be applied to computational simulations more conservatively, on a device-specific and sizing-specific basis.

\section{Study Limitations}

Limitations of our force-sensing technology have been described. $^{18,19}$ In the present study, which compared across ring types of different stiffnesses, it should be further noted that the rigid transducers themselves did have some consistent stiffening effect on all rings. Although this conceivably dampened the effect size when comparing the Physio with the Profile 3D, manual manipulation of the instrumented rings revealed that this effect was minor (ie, the Physio maintained its relative flexibility). Next, in our evaluation of the role of surgeon in $\mathrm{F}_{\mathrm{TD}}$, ring-annulus sizing was distributed asymmetrically across surgeons (Table 2). However, ring-annulus sizing did not significantly affect $\mathrm{F}_{\mathrm{TD}}$, suggesting this only minimally affected our findings. Last, we note that ANOVA testing across individual positions was less sensitive than other tests because of the multiple comparisons across 10 positions combined with the limited sample size. It is possible that some pairwise differences between suture positions went undetected.

\section{CONCLUSIONS}

Reducing the potential for harm associated with ring dehiscence is an important and evolving concept, which may be facilitated by greater understanding of the factors governing anchor retention. Forces acting on annuloplasty sutures are nonuniform and influenced by ring type, ring-annulus sizing, suture position, $\mathrm{LVP}_{\max }$, and surgeon (knot-tying technique). In total, these findings motivate increased standardization of suture tying technique and enhanced design and regulation of annuloplasty rings and related valve-repair devices. In pursuit of ring designs that preferentially reduce loading along the weaker posterior mitral annulus, further study should clarify the isolated effects of ring shape and ring stiffness.

\section{Conflict of Interest Statement}

Authors have nothing to disclose with regard to commercial support.

The authors thank Branislav Vidakovic, $\mathrm{PhD}$, of Georgia Institute of Technology, who provided biostatistical consulting expertise.

\section{References}

1. De Bonis M, Ferrara D, Taramasso M, Calabrese MC, Verzini A, Buzzatti N, et al. Mitral replacement or repair for functional mitral regurgitation in dilated and ischemic cardiomyopathy: is it really the same? Ann Thorac Surg. 2012;94:44-51.

2. Acker MA, Parides MK, Perrault LP, Moskowitz AJ, Gelijns AC, Voisine P, et al. Mitral-valve repair versus replacement for severe ischemic mitral regurgitation. N Engl J Med. 2014;370:23-32.

3. Kron IL, Hung J, Overbey JR, Bouchard D, Gelijns AC, Moskowitz AJ, et al. Predicting recurrent mitral regurgitation after mitral valve repair for severe ischemic mitral regurgitation. J Thorac Cardiovasc Surg. 2015;149:752-61. e751.

4. Braun J, Klautz RJ. Mitral valve surgery in low ejection fraction, severe ischemic mitral regurgitation patients: should we repair them all? Curr Opin Cardiol. 2012;27:111-7.

5. Hung J, Papakostas L, Tahta SA, Hardy BG, Bollen BA, Duran CM, et al. Mechanism of recurrent ischemic mitral regurgitation after annuloplasty continued LV remodeling as a moving target. Circulation. 2004;110:II-85-90.

6. Borger MA, Alam A, Murphy PM, Doenst T, David TE. Chronic ischemic mitral regurgitation: repair, replace or rethink? Ann Thorac Surg. 2006;81: 1153-61.

7. Kron IL, Acker MA, Adams DH, Ailawadi G, Bolling SF, Hung JW, et al. 2015 The American Association for Thoracic Surgery Consensus Guidelines: ischemic mitral valve regurgitation. J Thorac Cardiovasc Surg. 2016;151:940-56.

8. Cerfolio RJ, Orszulak TA, Pluth JR, Harmsen WS, Schaff HV. Reoperation after valve repair for mitral regurgitation: early and intermediate results. $J$ Thorac Cardiovasc Surg. 1996;111:1177-84.

9. Dumont E, Gillinov AM, Blackstone EH, Sabik JF, Svensson LG, Mihaljevic T, et al. Reoperation after mitral valve repair for degenerative disease. Ann Thorac Surg. 2007;84:444-50. 
10. Gillinov AM, Cosgrove DM, Lytle BW, Taylor PC, Stewart RW, McCarthy PM, et al. Reoperation for failure of mitral valve repair. J Thorac Cardiovasc Surg. 1997;113:467-75.

11. Ramakrishna H. Incidental TOE finding-Carpentier mitral annuloplasty ring dehiscence during heart transplantation. Ann Card Anaesth. 2008;11:49.

12. Levack MM, Vergnat M, Cheung AT, Acker MA, Gorman RC, Gorman JH III. Annuloplasty ring dehiscence in ischemic mitral regurgitation. Ann Thorac Surg. 2012;94:2132.

13. Shapira AR, Stoddard MF, Dawn B. Dehiscence of mitral annuloplasty ring. Circulation. 2005;112:e305.

14. Jones-Haywood M-M, Combs C, Pu M, Gandhi SK, Dhawan R, Tempe DK. Percutaneous closure of mitral paravalvular leak. J Cardiothorac Vasc Anesthes. 2013;27:168-77.

15. Tsang W, Wu G, Rozenberg D, Mosko J, Leong-Poi H. Early mitral annuloplasty ring dehiscence with migration to the descending aorta. J Am Coll Cardiol. 2009; $54: 1629$.

16. Ciobanu AO, Griffin SC, Bennett S, Vinereanu D. Catastrophic mitral prosthesis dehiscence diagnosed by three-dimensional transesophageal echocardiography. J Clin Ultrasound. 2014:42:249-51.

17. Pierce EL, Gentile J, Siefert AW, Gorman RC, Gorman JH, Yoganathan AP. Real-time recording of annuloplasty suture dehiscence reveals a potential mechanism for dehiscence cascade. J Thorac Cardiovasc Surg. 2016;152:e15-7.

18. Pierce EL, Siefert AW, Paul DM, Wells SK, Bloodworth CH, Takebayashi S, et al. How local annular force and collagen density govern mitral annuloplasty ring dehiscence risk. Ann Thorac Surg. 2016;102:518-26.

19. Siefert AW, Pierce EL, Lee M, Jensen MØ, Aoki C, Takebayashi S, et al. Suture forces in undersized mitral annuloplasty: novel device and measurements. Ann Thorac Surg. 2014;98:305-9.

20. Wong VM, Wenk JF, Zhang Z, Cheng G, Acevedo-Bolton G, Burger M, et al. The effect of mitral annuloplasty shape in ischemic mitral regurgitation: a finite element simulation. Ann Thorac Surg. 2012;93:776-82.

21. Khamooshian A, Buijsrogge MP, de Heer F, Gründeman PF. Mitral valve annuloplasty rings: review of literature and comparison of functional outcome and ventricular dimensions. Innovations (Phila). 2014;9:399-415.

22. Lange R, Guenther T, Kiefer B, Noebauer C, Goetz W, Busch R, et al. Mitral valve repair with the new semirigid partial Colvin-Galloway Future annuloplasty band. J Thorac Cardiovasc Surg. 2008;135:1087-93. e1084.
23. National Research Council (US) Committee for the Update of the Guide for the Care and Use of Laboratory Animals. Guide for the Care and Use of Laboratory Animals. National Institutes of Health Publication 85-23. Bethesda, MD: National Institutes of Health; 1996.

24. Scheffe H. The Analysis of Variance. New York: John Wiley \& Sons; 1959.

25. Box GE. Some theorems on quadratic forms applied in the study of analysis of variance problems, I. Effect of inequality of variance in the one-way classification. Ann Math Stat. 1954;25:290-302.

26. Horsnell G. The effect of unequal group variances on the F-test for the homogeneity of group means. Biometrika. 1953;40:128-36.

27. Glass GV, Peckham PD, Sanders JR. Consequences of failure to mee assumptions underlying the fixed effects analyses of variance and covariance. Rev Educ Res. 1972;42:237-88.

28. Rankin JS, Arentzen CE, McHale PA, Ling D, Anderson RW. Viscoelastic properties of the diastolic left ventricle in the conscious dog. Circ Res. 1977; 41:37-45.

29. Rusy B, Komai H. Anesthetic depression of myocardial contractility: a review of possible mechanisms. Anesthesiology. 1987;67:745-66.

30. McCarthy PM. A chain is only as strong as its weakest link. J Thorac Cardiovasc Surg. 2016;152:e19-20.

31. Morrisson TM. Using Modeling and Simulation for Medical Device Innovation: Virtual Patients for Regulatory Decision Making. Food and Drug Administration Science Writers Symposium. Silver Spring, MD; 2015. Available at: http://www.fda.gov/downloads/ScienceResearch/MeetingsCon ferencesandWorkshops/ScienceWritersSymposium/UCM467959.pdf. Accessed November 10, 2016.

32. Food and Drug Administration. Reporting of Computational Modeling Studies in Medical Device Submissions: Guidance for Industry and Food and Drug Administration Staff. Food and Drug Administration, Center for Devices and Radiological Health, Office of Device Evaluation; 2014. Available at: http:// www.fda.gov/downloads/MedicalDevices/DeviceRegulationandGuidance/ GuidanceDocuments/UCM381813.pdf. Accessed November 10, 2016.

Key Words: mitral valve, annuloplasty, suture, dehiscence, force, medical device design, recurrent, regurgitation 


\section{SUPPLEMENTAL MATERIALS AND METHODS Suture Force Measurement Technology}

Suture force transducers are shown in Figure 1. Each transducer consisted of a strain-gage sensing element (Figure 1, A, arrow c) bonded to a biocompatible (316L stainless steel) bracket-shaped spring element. Ten transducers were fixtured around the circumference of an annuloplasty ring of interest by passing dedicated sutures through the ring's suture cuff and the transducer's fixturing holes (Figure 1, A, arrow a). Wiring (Figure 1, A, arrow d) connected the strain gage to data acquisition hardware and custom LabVIEW-based software (all from National Instruments, Austin, Tex).

Once a suture was looped through a transducer's mounting holes (Figure 1, A, arrow $b$ ), any tension on that suture passed through the strain gage and generated a detectable voltage response. Suture force is detected as a positive signal. The temporal limit of the system was $0.6 \mathrm{~ms}$, and the force resolution limit was $0.1 \mathrm{~N}$. Calibration of each transducer was performed before and after all experiments, using forces in excess of those anticipated in vivo. This process demonstrated a highly linear voltage-force relationship $\left(\mathrm{R}^{2}>0.99\right.$ in all cases). Given the dimensions of the transducers and the positions of the mounting holes, an instrumented ring was effectively 1 ring size larger than in its uninstrumented form.

\section{Experimental Protocol}

Each of 23 healthy Dorsett hybrid sheep was intubated, anesthetized, and ventilated with isofluorane $(1.5 \%$ to $2 \%$ ) and oxygen. Surface electrocardiogram and arterial blood pressure were monitored, and baseline apical echocardiography was performed (2-dimensional, 3-dimensional, color Doppler, and pulsed-wave Doppler). After establishing cardiopulmonary bypass, a left atriotomy was performed to expose the mitral annulus. The flaccid annulus was sized using the sizer set corresponding to either ring type, per manufacturer instructions; either an undersized (2 sizes down) or true-sized ring of that type was selected. Ten Y-31 Ti $\cdot$ Cron sutures (Medtronic, Dublin, Ireland) were passed in the mitral annulus, through evenly spaced positions corresponding to the 10 suture force transducers affixed to the annuloplasty ring. These sutures were passed through the mounting holes of the transducers' measurement arms (Figure 1, A, arrow $b$ ). Just before suture tie-down, all force transducer signals were zeroed and recording was begun. Recording continued until after animal sacrifice. Sutures were tied in a consistent sequence (left trigone, right trigone, then clockwise from 11 o'clock). After left atrium closure, the animal was weaned from cardiopulmonary bypass over approximately 30 minutes. A high-fidelity pressure transducer was passed to the left ventricle for continuous LVP recording. On the reestablishment of baseline hemodynamics, (4.0 L/min cardiac output, $100 \mathrm{~mm} \mathrm{Hg} \mathrm{LVP}_{\text {max }}$ ), real-time 3-dimensional and standard 2-dimensional echocardiography were performed to verify normal ventricular function and transvalvular pressure gradient. Suture forces were recorded at $\mathrm{LVP}_{\max }=100 \mathrm{~mm} \mathrm{Hg}$, and subsequently under increased afterload (ie, $\mathrm{LVP}_{\max }=125$ and $150 \mathrm{~mm} \mathrm{Hg}$ ). Elevated $\mathrm{LVP}_{\max }$ was achieved via a continuous infusion of neosynephrine and dobutamine. After in vivo data collection, the animal was euthanized with an injection of $80 \mathrm{mEq} \mathrm{KCl}$. The heart was explanted and examined to verify sutures were placed correctly and remained intact. 


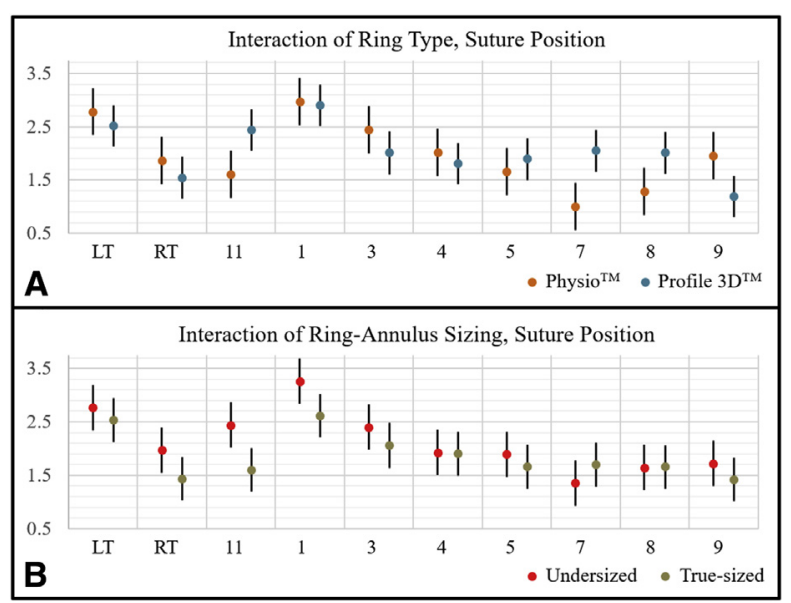

FIGURE E1. Additional $\mathrm{F}_{\mathrm{C}}$ ANOVA results, revealing interactions between suture position and either (A) ring type or (B) ring-annulus sizing. Data are shown in circumferential order. All plots reveal force means and $95 \%$ confidence intervals $[\mathrm{N}]$; pairs whose $95 \%$ confidence intervals do not overlap differ significantly $(P<.05)$. $L T$, Left trigone; $R T$, right trigone.
TABLE E1. Results of all analysis of variance models before Tukey's honestly significance difference post hoc analysis

\begin{tabular}{lll}
\hline & F & $P$ value \\
\hline Model 1 ( $\left.\mathrm{F}_{\mathrm{TD}}\right)$ & & \\
$\quad$ Main effects & & \\
$\quad$ Ring type & 0.76 & .385 \\
$\quad$ Ring-annulus sizing & 2.08 & .152 \\
$\quad$ Suture position & 1.93 & .051 \\
Interactions & & \\
$\quad$ Ring type: ring-annulus & 0.03 & .855 \\
$\quad$ sizing & & \\
$\quad$ Ring type: suture & 1.67 & .101 \\
$\quad$ position & & .621 \\
$\quad$ Ring-annulus sizing: & 0.8 & \\
$\quad$ suture position & & \\
Model 2 ( $\mathrm{F}_{\mathrm{TD}}$ ) & & .006 \\
Main effects & & .078 \\
$\quad$ Surgeon & 7.8 & \\
$\quad$ Suture position & 1.8 &
\end{tabular}

Model $3\left(\mathrm{~F}_{\mathrm{C}}\right)$

Main effects

$\mathrm{LVP}_{\max }$

16.87

$<.001$

Ring type

1.12

.29

Ring-annulus sizing

11.56

.001

Suture position

14.74

$<.001$

Interactions

$\mathrm{LVP}_{\max }$ : ring type

0.05

.95

$\mathrm{LVP}_{\text {max }}$ : ring-annulus

$$
\text { sizing }
$$

$\mathrm{LVP}_{\text {max }}$ : suture position

0.27

.999

Ring type: ring-annulus

sizing

Ring type: suture

6.59

$<.001$

position

Ring-annulus sizing:

2.16 suture position

\begin{tabular}{lrr} 
Model $4\left(\mathrm{~F}_{\mathrm{C}}\right)$ & \\
Main effects & & \\
$\quad \mathrm{LVP}_{\max }$ & 15.15 & $<.001$ \\
$\quad$ Ring type & 0.93 & .334 \\
$\quad$ Ring-annulus sizing & 10.66 & .001 \\
$\quad$ Suture region & 42.72 & $<.001$ \\
Interactions & & \\
$\quad$ LVP $_{\max }$ : ring type & 0.04 & .959 \\
LVP $_{\max }$ ring-annulus & 0.03 & .972 \\
$\quad$ sizing & & \\
$\quad$ LVP & 1.3 & .273 \\
$\quad$ Ring type: ring-annulus & 3.41 & .065 \\
$\quad$ sizing & & .731 \\
$\quad$ Ring type: suture region & 0.12 & .004 \\
$\quad$ Ring-annulus sizing: & 8.28 & \\
$\quad$ suture region & & \\
\hline
\end{tabular}

F- and $P$ values for main effects are obtained from ANOVA models that ignore factor interactions. $F_{T D}$, Tie-down force; $F_{C}$, cyclic contractile force; $L V P_{\max }$, maximum left ventricular pressure. 
TABLE E2. Mean (standard deviation) of cyclic contractile suture force for each ring type

\begin{tabular}{|c|c|c|c|c|}
\hline & Undersized Physio ring & True-sized Physio ring & Undersized Profile 3D ring & True-sized Profile 3D ring \\
\hline \multicolumn{5}{|c|}{ Peak LVP: 100 mm Hg } \\
\hline Left trigone & $3.06(1.14)$ & $1.72(0.60)$ & $1.66(1.07)$ & $2.32(1.15)$ \\
\hline 11 o'clock & $1.85(0.25)$ & $1.44(0.63)$ & $1.47(0.52)$ & $0.96(0.75)$ \\
\hline 1 o'clock & $1.63(1.10)$ & $1.09(0.72)$ & $2.48(0.85)$ & $1.72(1.06)$ \\
\hline Right trigone & $3.43(1.63)$ & $1.80(1.09)$ & $2.36(1.20)$ & $2.40(0.83)$ \\
\hline 3 o'clock & $2.2(1.76)$ & $1.81(0.43)$ & $1.98(0.79)$ & $1.65(1.06)$ \\
\hline 4 o'clock & $1.72(1.04)$ & $1.72(0.26)$ & $1.61(0.99)$ & $1.54(0.53)$ \\
\hline 5 o'clock & $1.36(0.44)$ & $1.51(0.54)$ & $1.81(1.02)$ & $1.47(0.62)$ \\
\hline 7 o'clock & $0.93(0.45)$ & $0.86(0.36)$ & $1.52(0.24)$ & 2.09 (1.09) \\
\hline 8 o'clock & $1.30(0.66)$ & $0.94(0.28)$ & $1.64(0.70)$ & $1.96(0.77)$ \\
\hline 9 o'clock & $1.73(1.03)$ & $1.80(0.83)$ & $1.22(0.89)$ & $0.87(0.58)$ \\
\hline All anterior & $2.49(1.31)$ & $1.51(0.77)$ & $1.99(0.99)$ & $1.85(1.08)$ \\
\hline All posterior & $1.54(1.00)$ & $1.44(0.60)$ & $1.63(0.85)$ & $1.60(0.85)$ \\
\hline \multicolumn{5}{|c|}{ Peak LVP: $125 \mathrm{~mm} \mathrm{Hg}$} \\
\hline Left trigone & $3.53(1.12)$ & $2.10(0.59)$ & $2.17(1.30)$ & $2.85(1.51)$ \\
\hline 11 o'clock & $2.12(0.31)$ & $1.55(0.64)$ & $1.72(0.70)$ & $1.23(0.84)$ \\
\hline 1 o'clock & $1.92(1.19)$ & $1.34(0.93)$ & $2.99(1.19)$ & $1.90(1.06)$ \\
\hline Right trigone & $3.67(1.61)$ & $2.26(1.42)$ & $2.92(1.36)$ & $2.93(0.85)$ \\
\hline 3 o'clock & $2.63(2.20)$ & $2.41(0.70)$ & $2.25(0.90)$ & $1.81(1.15)$ \\
\hline 4 o'clock & $2.04(1.29)$ & $2.16(0.32)$ & $1.95(1.13)$ & $1.78(0.63)$ \\
\hline 5 o'clock & $1.58(0.49)$ & $1.71(0.44)$ & $2.16(1.26)$ & $1.73(0.71)$ \\
\hline 7 o'clock & $0.99(0.46)$ & $1.03(0.36)$ & $1.74(0.27)$ & $2.47(1.30)$ \\
\hline 8 o'clock & $1.48(0.60)$ & $1.16(0.45)$ & $1.85(0.81)$ & $2.24(0.76)$ \\
\hline 9 o'clock & $1.98(1.20)$ & $1.87(1.01)$ & $1.44(0.96)$ & $1.02(0.64)$ \\
\hline All anterior & $2.81(1.34)$ & $1.81(0.96)$ & $2.45(1.22)$ & $2.23(1.26)$ \\
\hline All posterior & $1.78(1.22)$ & $1.72(0.74)$ & $1.90(0.91)$ & $1.84(0.96)$ \\
\hline \multicolumn{5}{|c|}{ Peak LVP: $150 \mathrm{~mm} \mathrm{Hg}$} \\
\hline Left trigone & $3.85(1.22)$ & $2.45(0.67)$ & $2.57(1.49)$ & $3.33(1.54)$ \\
\hline 11 o'clock & $2.49(0.41)$ & $1.74(0.71)$ & $2.15(0.76)$ & $1.73(0.94)$ \\
\hline 1 o'clock & $2.00(1.19)$ & $1.64(1.20)$ & $3.49(1.20)$ & $2.12(0.99)$ \\
\hline Right trigone & $3.97(1.75)$ & $2.73(1.60)$ & $3.38(1.36)$ & $3.29(1.19)$ \\
\hline 3 o'clock & $2.95(2.43)$ & $2.67(0.73)$ & $2.33(0.99)$ & $2.04(1.14)$ \\
\hline 4 o'clock & $2.07(1.35)$ & $2.41(0.39)$ & $2.08(1.23)$ & $1.93(0.66)$ \\
\hline 5 o'clock & $1.79(0.57)$ & $1.98(0.45)$ & $2.51(1.50)$ & $1.76(0.73)$ \\
\hline 7 o'clock & $1.14(0.66)$ & $1.07(0.42)$ & $1.86(0.33)$ & $2.57(1.31)$ \\
\hline 8 o'clock & $1.60(0.62)$ & $1.26(0.56)$ & $2.05(0.98)$ & $2.27(0.76)$ \\
\hline 9 o'clock & $2.25(1.44)$ & $2.07(1.04)$ & $1.60(0.92)$ & $1.05(0.7)$ \\
\hline All anterior & $3.08(1.44)$ & $2.14(1.13)$ & $2.90(1.28)$ & $2.62(1.33)$ \\
\hline All posterior & 1.97 (1.36) & $1.91(0.83)$ & $2.07(1.02)$ & $1.94(0.98)$ \\
\hline
\end{tabular}

$L V P$, Left ventricular pressure. 